\title{
Activation of hatching in diapaused and quiescent Globodera pallida
}

\author{
JUAN E. PALOMARES-RIUS ${ }^{1} *$, JOHN T. JONES ${ }^{1}$, PETER J. COCK ${ }^{1}$, PABLO CASTILLO ${ }^{2}$ \\ and VIVIAN C. BLOK ${ }^{1}$ \\ ${ }^{1}$ Cell and Molecular Sciences, Fames Hutton Institute, Invergowrie, Dundee DD2 5DA, UK \\ ${ }^{2}$ Department of Plant Protection, Institute for Sustainable Agriculture (IAS-CSIC), Cordoba, 14080, Cordoba, Campus de \\ Excelencia Internacional Agroalimentario, ceiA3, Spain
}

(Received 22 June 2012; revised 25 September 2012; accepted 11 October 2012; first published online 20 December 2012)

\begin{abstract}
SUMMARY
The potato cyst nematodes (PCN) Globodera pallida and G. rostochiensis are major pests of potatoes. The G. pallida (and G. rostochiensis) life cycle includes both diapause and quiescent stages. Nematodes in dormancy (diapause or quiescent) are adapted for long-term survival and are more resistant to nematicides. This study analysed the mechanisms underlying diapause and quiescence. The effects of several compounds (8Br-cGMP, oxotremorine and atropine) on the activation of hatching were studied. The measurements of some morphometric parameters in diapaused and quiescent eggs after exposure to PRD revealed differences in dorsal gland length, subventral gland length and dorsal gland nucleolus. In addition, the expression of 2 effectors (IVg9 and cellulase) was not induced in diapaused eggs in water or PRD, while expression was slightly induced in quiescent eggs. Finally, we performed a comparative study to identify orthologues of $C$. elegans diapause related genes in plant-parasitic nematodes (G. pallida, Meloidogyne incognita, M. hapla and Bursaphelenchus xylophilus). This analysis suggested that it was not possible to identify G. pallida orthologues of the majority of $C$. elegans genes involved in the control of dauer formation. All these data suggest that G. pallida may use different mechanisms to $C$. elegans in regulating the survival stage.
\end{abstract}

Key words: hatching, cGMP, muscarinic pathway, potato cyst nematodes, root diffusate.

\section{INTRODUCTION}

Nematodes, like many organisms, are adapted to survive in unfavourable environmental conditions and different strategies are used by different species depending on their ecological niche. The free-living model nematode Caenorhabditis elegans will enter the dauer stage, a larval stage geared for survival, when unfavourable environmental conditions (such as crowding or lack of food) are encountered (Fielenbach and Antebi, 2008). Animal and plantparasitic nematodes frequently use a survival stage in order to synchronize their life cycle with that of their hosts in order to optimize their chances of successful invasion (Perry, 1989). Animal parasitic nematodes are frequently activated after the parasite is exposed to conditions found in the gut of animals (high $\mathrm{pH}$, increased $\mathrm{CO}_{2}$ ), while in the case of some plantparasitic nematodes, hatching is activated by host root diffusates. The sequence of events from perception of the hatching stimulus to hatching varies considerably between species (Perry, 1989). This linking of host and plant parasite is a form of quiescence and is restricted to species that are hostspecific.

* Corresponding author: Cell and Molecular Sciences, James Hutton Institute, Invergowrie, Dundee DD2 5DA, UK. E-mail: juapariu@hotmail.com
The life cycle of cyst nematodes begins when the vermiform second-stage juvenile (J2) hatches and invades the roots of host plants. Each individual nematode feeds on a group of cells in the pericycle, cortex or endodermis, transforming them into a syncytium or transfer cell. The nematode remains sedentary for the rest of its development, as it passes through 2 more juvenile stages to become either male or female. Males are active and leave the root to find and fertilize females. Females retain the eggs inside their bodies and the first moult from J1 to J2 occurs inside the egg. When the females are fully mature they die and their cuticle hardens and turns brown to become a protective cover (the cyst) around the eggs. In some species, most often those in temperate zones, the juvenile nematodes may enter diapause. Diapause can be facultative (responsive to host status) or obligate. Diapause is broken after exposure to a period of cold (winter) and in host-specific species diapause is followed by quiescence. However, other cyst nematodes enter diapause in order to avoid summer conditions as seen for Heterodera avenae in Australia (Banyer and Fisher, 1971). If adverse conditions persist after diapause has ended, the larvae enter a quiescent state (Perry and Moens, 2011). Quiescence is defined as dormancy (lowered metabolism) under unfavourable conditions (no presence of host plants) with development readily resumed as 
conditions become favourable (hatching in presence of growing host roots). Nematodes in dormancy (diapause or quiescent) can survive longer $(\sim 30$ years in certain species) and are more resistant to nematicides (Spears, 1968).

The potato cyst nematodes (PCN) Globodera pallida and G. rostochiensis are major plant-parasitic nematode pests of potato production and are found infesting fields as mixtures of both species or alone (Pylypenko et al. 2005). The G. pallida (and $G$. rostochiensis) life cycle includes both diapause and quiescent stages described above. It is thought that changes in the feeding site occurring as the host plant ages may influence the feeding female, which in turn may trigger biochemical changes in the juvenile that promote entry into diapause (Perry and Gaur, 1996; Perry and Moens, 2011). The survival stage of Globodera pallida is not a true dauer stage, although other plant-parasitic nematodes such as Bursaphelenchus (Kikuchi et al. 2011) and Anguina (Bird and Buttrose, 1974) do have dauer stages. However, some morphological characteristics of $\mathrm{J} 2$ cyst nematodes are similar to those of dauer stages including resistance to detergents, intestinal microvilli and numerous lipid storage vesicles (reviewed by Elling et al. 2007). Gene expression studies do not support the idea of a broadly conserved gene expression pattern between the dauer stage in $C$. elegans and infective $\mathrm{J} 2$ of $H$. glycines (Elling et al. 2007). However, the genes involved in control of the formation of dauer or other arrested life stages have not been characterized from the genome of cyst nematodes and it is not known whether such sequences are involved in the processes leading to hatching arrest in diapaused eggs when conditions are favourable for hatching.

Dauer formation has been extensively studied in C. elegans giving insights into the signalling pathways and molecular mechanisms that govern this developmental transition (Hu, 2007; Fielenbach and Antebi, 2008). Identified components of the control of dauer formation include pathways that control sensory neuron structure and function including cGMP signalling and serotonergic neurotransmission, which impinge on TGF- $\beta$ and insulin/IGF-1 signalling. These pathways converge on steroid hormone receptor transcriptional cascades, which are instrumental in the dauer decision (Fielenbach and Antebi, 2008). Muscarinic agonists promote insulin release both in vivo and in vitro in mammals (Miller, 1981; Hawdon and Schad, 1993). Oxotremorine is a muscarinic agonist which has experimentally been shown to be important in the diapause removal from other nematodes (Tissenbaum et al. 2000). Similar signalling pathways are present in Ancylostoma caninum and $A$. ceylanicum (Tissembuam et al. 2000; Hawdon and Datu, 2003; Brand and Hawdon, 2004), but differences have been found with others including Nippostrongylus brasiliensis
(Huang et al. 2010). Caenorhabditis briggsae, the closest relative to $C$. elegans that has been studied in some detail, lacks the beta-insulin molecule involved in signal transduction encoded by $d a f-28$ and this is also true for Meloidogyne hapla (Opperman et al. 2008). It is therefore clear that divergence from the genetic pathway described for $C$. elegans is present within the phylum Nematoda.

Few studies on the signalling pathways involved in diapause/quiescence in plant nematodes have been performed. Atkinson et al. (1987) showed that exposure to the signalling molecules cAMP and cGMP (which are implicated in the dauer signalling pathway in C.elegans) reduced normal hatching (exit from the quiescent state) in the presence of root diffusates. However, these effects have not been studied in detail in G. pallida and the response of nematodes in diapause has not been analysed.

The objectives of this study were to (i) determine whether the muscarinic pathway is involved in recovery from diapause and/or quiescence in G. pallida, (ii) investigate the presence of genes in G. pallida and other plant-parasitic nematodes related to those implicated in dauer formation in $C$. elegans and (iii) to compare the responses of unhatched juveniles in diapause or quiescence upon stimulation with host root diffusate.

\section{MATERIALS AND METHODS}

\section{Cultivation of $\mathrm{G}$. pallida populations}

Cysts from G. pallida (population Lindley) were multiplied as greenhouse cultures in $10 \mathrm{~cm}$ pots on the susceptible potato cultivar Désirée. Cysts were extracted from soil by thoroughly mixing infested soil with water in a plastic bucket and settling for $15 \mathrm{sec}$. The supernatant was poured through a $750 \mu \mathrm{m}$-pore sieve nested over a $250 \mu \mathrm{m}$-pore sieve. Cysts were collected from the finer mesh sieve and kept at $4{ }^{\circ} \mathrm{C}$ until use for hatching and gene expression experiments. Quiescent cysts and cysts in diapause were obtained from plants grown in 2009 and 2010, respectively, under identical conditions. Cysts from 2009 had been exposed to several months at $4{ }^{\circ} \mathrm{C}$, conditions that are known to break diapause (Muhammad, 1994).

\section{Hatching experiments}

To prepare potato root diffusate (PRD), roots of 3 -week-old potato plants (cv. Désirée) growing in peat were washed, placed in $250 \mathrm{ml}$ of distilled water and kept at room temperature (approximately $20^{\circ} \mathrm{C}$ ) for $2 \mathrm{~h}$. The plant was removed and the water containing root diffusates was filtered through Whatman filter paper and a $0.45 \mu \mathrm{m}$ syringe filter to remove contaminating micro-organisms. The resulting PRD was stored at $4{ }^{\circ} \mathrm{C}$ until required. Cysts selected for 
experiments were chosen on the basis of their size homogeneity. In previous work at JHI, hatch rates from both samples were in excess of $75 \%$ after 3 weeks in PRD (not shown). Before use, cysts were soaked at $20^{\circ} \mathrm{C}$ for 5 days in sterile tap water. A 24 -well plate assay system was used in the experiment containing groups of 10 cysts in each well. Each well was considered a biological replicate. After this period, the sterile tap water was removed and $1 \mathrm{ml}$ of new solution (sterile distilled water or PRD) along with the agonist or antagonist of the muscarinic pathway, supplemented with antibiotics and fungicides (100 units $/ \mathrm{ml}$ penicillin, $100 \mu \mathrm{g} / \mathrm{ml}$ streptomycin, $100 \mu \mathrm{g} / \mathrm{ml}$ gentamycin and $2 \cdot 5 \mu \mathrm{g} / \mathrm{ml}$ amphotericin B) was added. Control treatments including all the antibiotics and fungicides alone were used to confirm that these did not affect hatching (data not shown). Oxotremorine was used as an agonist of the muscarinic pathway at concentrations of $0 \cdot 1,0.5$ and $1 \mathrm{mM}$; while atropine was used as antagonist at 1, 2.5 and $5 \mathrm{mM}$. 8Br-cGMP was used at $0 \cdot 1,0.5$ and $1 \mathrm{mM}$ to promote hatching as previously described for other nematodes (Tissembaum et al. 2000). All experiments were carried out in the dark at $20^{\circ} \mathrm{C}$. All drugs and antibiotics/fungicides used were sourced from Sigma (St Louis, MO, USA). These concentrations of agonists/antagonists were as previously used in other nematodes for diapause recovery (Tissenbaum et al. 2000; Hawdon and Datu, 2003). Nematode hatching was determined daily and the solutions were not changed until 7 days. At this time the solutions and juveniles were removed and PRD was added to all the wells and hatching of the remaining eggs inside the cysts was observed for 2-3 additional days to assess mortality rates. Each treatment was done in triplicate, making 30 cysts per treatment, and each experiment was repeated twice.

\section{Identification of $\mathrm{G}$. pallida homologues of C. elegans diapause-related genes}

Orthologues of C.elegans diapause-related genes from G. pallida were obtained using a reciprocal blasting strategy using the putative protein sequences from annotated genomes of G. pallida (ftp://ftp.sanger.ac. uk/pub/pathogens/Globodera/pallida/), Meloidogyne incognita (http://www.inra.fr/meloidogyne_incogni ta/genomic_resources), Meloidogyne hapla (http:// supfam.cs.bris.ac.uk/SUPERFAMILY/cgi-bin/ gen_list.cgi? ?enome $=\mathrm{Mh}$ ) and Bursaphelenchus $x y$ lo philus (ftp://ftp.sanger.ac.uk/pub/pathogens/Bursa phelenchus/xylophilus/Assembly-v1.2/). A local installation of Galaxy (Goecks et al. 2010) was used to run NCBI BLAST + blastp (Altschul et al. 1990), filter the results, and perform a Reciprocal Best Hit (RBH) analysis (custom Python script). For the $\mathrm{RBH}$, threshold values of $\geqslant 40 \%$ sequence identity, $\geqslant 70 \%$ coverage, and $\leqslant 0.001$ were used, sorting on bit-score. The less stringent analyses used $\geqslant 30 \%$ sequence identity, $\geqslant 50 \%$ coverage, and $\leqslant 0.001$ e-value.

\section{RNA extraction, primer design and real-time PCR}

Dried cysts, cysts soaked for 5 days in distilled sterile water, cysts exposed $24 \mathrm{~h}$ to PRD and J2s were studied from quiescent and diapaused nematodes. Eggs were released from cysts using a tissue homogenizer with a clearance of $0 \cdot 46-0.54 \mathrm{~mm}$ between the glass pestle and the homogenizer tube. Cyst walls were removed from eggs by pouring the solution through a $100 \mu \mathrm{m}$-pore sieve nested over a $5 \mu \mathrm{m}$-pore sieve. Eggs were concentrated by decantation and centrifugation and kept at $-80^{\circ} \mathrm{C}$ until use.

Total RNA was extracted using the RNeasy® Plus Micro Kit (Qiagen, Hilden, Germany) following the manufacturer's instructions. DNA digestion was conducted on fiber glass during RNA extraction using an RNase-Free DNase set (Qiagen, Hilden, Germany) following the manufacturer's instructions. Total RNA was quantified using a Nanodrop 1000 Spectrophotometer (Thermo Scientific, Waltham, MA, USA) and approximately $700 \mathrm{ng}$ of RNA was used for cDNA synthesis using QuantiTect ${ }^{\circledR}$ Reverse Transcription Kit (Qiagen, Hilden, Germany) following the manufacturer's instructions. The cDNA was diluted 1:20 with PCR grade water and then used in real-time PCR reactions containing $\mathrm{iQ}^{\mathrm{TM}} \mathrm{SYBR}{ }^{\circledR}$ Green Supermix (Bio-Rad, Hercules, CA, USA) with a primer concentration of $200 \mathrm{mM}$ each and $5 \mu \mathrm{l}$ of the diluted cDNA in a final volume of $15 \mu \mathrm{l}$. Cycling conditions consisted of 1 cycle of denaturing at $94^{\circ} \mathrm{C}$ for $3 \mathrm{~min}$ followed by 40 cycles of $15 \mathrm{~s}$ denaturing at $94^{\circ} \mathrm{C}, 30 \mathrm{~s}$ annealing at $55^{\circ} \mathrm{C}$ and $30 \mathrm{~s}$ extension at $72^{\circ} \mathrm{C}$, finishing with an final extension of $5 \mathrm{~min}$ at $72^{\circ} \mathrm{C}$. All real-time $\mathrm{PCR}$ assays were performed using a Chromo $4^{\mathrm{TM}}$ Real-Time Detector (Bio-RAD, Hercules, CA, USA). PCR products obtained from the different extractions were verified by performing a melting curve analysis and visualization of PCR products on $1.5 \%$ agarose gels stained with SYBR® Safe DNA gel stain (Invitrogen Corp., Carlsbad, CA, USA) following the manufacturer's instructions in order to verify the size of the product obtained in the different extractions. All samples were run in triplicate and results were analysed using Gene Expression Macro $^{\text {TM }}$ ver. 1.1 (Bio-Rad, Hercules, CA, USA), software provided by the manufacturer.

To determine whether the expression of parasitism genes was activated by TRD in quiescent or diapaused eggs, the relative expression of 2 genes $\operatorname{IVg} 9 \quad(\mathrm{gb}|\mathrm{GO} 249406.1|)$ and cellulase (gb| GO249479.1|), which are expressed in the dorsal and in the subventral pharyngeal glands, respectively (Jones et al. 2009), was quantified in relation to eif $A 4$ (translation initiation factor) (GPLIN_000384600 protein), from the G. pallida genome assembly, 
Table 1. Area under graph from cumulative hatch of Globodera pallida over 7 days of incubation at $20^{\circ} \mathrm{C}$ with different testing compounds diluted in water or in potato root diffusate $(\mathrm{PRD})^{\mathrm{A}}$

(Data shown are means \pm standard deviations.)

\begin{tabular}{|c|c|c|}
\hline \multirow[b]{2}{*}{ Treatments } & \multicolumn{2}{|l|}{ Populations } \\
\hline & E-2009 & E-2010 \\
\hline Control-water & $24 \cdot 3 \pm 11 \cdot 3 \mathrm{c}$ & $1 \cdot 5 \pm 2 \cdot 5 \mathrm{~ns}$ \\
\hline $\begin{array}{l}\text { 8-Br-cGMP-water } \\
1 \mathrm{mM}\end{array}$ & $267 \cdot 9 \pm 147 \cdot 2 \mathrm{a}$ & $2 \cdot 0 \pm 2 \cdot 8 \mathrm{~ns}$ \\
\hline $\begin{array}{l}\text { 8-Br-cGMP-water } \\
0.5 \mathrm{mM}\end{array}$ & $209 \cdot 9 \pm 95 \cdot 4 \mathrm{a}$ & $6 \cdot 4 \pm 4 \cdot 5 \mathrm{~ns}$ \\
\hline $\begin{array}{l}\text { 8-Br-cGMP-water } \\
0.1 \mathrm{mM}\end{array}$ & $82 \cdot 3 \pm 70 \cdot 4 \mathrm{~b}$ & $4 \cdot 0 \pm 6 \cdot 5 \mathrm{~ns}$ \\
\hline Control-PRD & $4697 \cdot 4 \pm 2304 \cdot 6 \mathrm{~ns}$ & $359 \cdot 4 \pm 254.9 \mathrm{a}$ \\
\hline $\begin{array}{l}\text { 8-Br-cGMP-PRD } \\
1 \mathrm{mM}\end{array}$ & $3628 \cdot 7 \pm 794 \cdot 8 \mathrm{~ns}$ & $155 \cdot 2 \pm 75 \cdot 7 \mathrm{~b}$ \\
\hline $\begin{array}{l}\text { 8-Br-cGMP-PRD } \\
0.5 \mathrm{mM}\end{array}$ & $4968 \cdot 1 \pm 902 \cdot 2 \mathrm{~ns}$ & $361 \cdot 5 \pm 138 \cdot 1 \mathrm{a}$ \\
\hline $\begin{array}{l}\text { 8-Br-cGMP-PRD } \\
0 \cdot 1 \mathrm{mM}\end{array}$ & $6126 \cdot 5 \pm 1908 \cdot 0 \mathrm{~ns}$ & $514 \cdot 8 \pm 287 \cdot 1 \mathrm{a}$ \\
\hline Control-water & $24 \cdot 3 \pm 11 \cdot 3 \mathrm{~ns}$ & $1 \cdot 5 \pm 2 \cdot 5 \mathrm{~ns}$ \\
\hline $\begin{array}{l}\text { Oxotremorine- } \\
\text { water } 1 \mathrm{mM}\end{array}$ & $21 \cdot 2 \pm 10 \cdot 2 \mathrm{~ns}$ & $1 \cdot 3 \pm 2 \cdot 1 \mathrm{~ns}$ \\
\hline $\begin{array}{l}\text { Oxotremorine- } \\
\text { water } 0.5 \mathrm{mM}\end{array}$ & $19 \cdot 1 \pm 12 \cdot 6 \mathrm{~ns}$ & $1 \cdot 2 \pm 2 \cdot 9 \mathrm{~ns}$ \\
\hline $\begin{array}{l}\text { Oxotremorine- } \\
\text { water } 0 \cdot 1 \mathrm{mM}\end{array}$ & $14 \cdot 4 \pm 12 \cdot 6 \mathrm{~ns}$ & $1 \cdot 0 \pm 1 \cdot 8 \mathrm{~ns}$ \\
\hline Control-PRD & $4697 \cdot 5 \pm 2304 \cdot 6 \mathrm{~ns}$ & $359 \cdot 4 \pm 254.9 \mathrm{~ns}$ \\
\hline $\begin{array}{l}\text { Oxotremorine- } \\
\text { PRD } 1 \mathrm{mM}\end{array}$ & $5049 \cdot 7 \pm 890 \cdot 9 \mathrm{~ns}$ & $343 \cdot 6 \pm 270 \cdot 6 \mathrm{~ns}$ \\
\hline $\begin{array}{l}\text { Oxotremorine- } \\
\text { PRD } 0.5 \mathrm{mM}\end{array}$ & $5762 \cdot 4 \pm 1213 \cdot 7 \mathrm{~ns}$ & $374 \cdot 8 \pm 260 \cdot 7 \mathrm{~ns}$ \\
\hline $\begin{array}{l}\text { Oxotremorine- } \\
\text { PRD } 0.1 \mathrm{mM}\end{array}$ & $4061 \cdot 9 \pm 1158 \cdot 4 \mathrm{~ns}$ & $458 \cdot 4 \pm 222 \cdot 7 \mathrm{~ns}$ \\
\hline Control-water & $24 \cdot 3 \pm 11 \cdot 3 \mathrm{~ns}$ & $0 \cdot 5 \pm 1 \cdot 2$ \\
\hline $\begin{array}{l}\text { Atropine-water } \\
5 \mathrm{mM}\end{array}$ & $24 \cdot 1 \pm 22 \cdot 4 \mathrm{~ns}$ & $0,0^{\mathrm{B}}$ \\
\hline $\begin{array}{l}\text { Atropine-water } \\
2.5 \mathrm{mM}\end{array}$ & $14 \cdot 5 \pm 13 \cdot 4 \mathrm{~ns}$ & $2 \cdot 8 \pm 5 \cdot 4$ \\
\hline $\begin{array}{l}\text { Atropine-water } \\
0.5 \mathrm{mM}\end{array}$ & $15 \cdot 1 \pm 13 \cdot 1 \mathrm{~ns}$ & $0 \cdot 3 \pm 0 \cdot 6$ \\
\hline Control-PRD & $4697 \cdot 5 \pm 2304 \cdot 6 \mathrm{a}$ & $359 \cdot 4 \pm 254 \cdot 9 \mathrm{a}$ \\
\hline $\begin{array}{l}\text { Atropine-PRD } \\
5 \mathrm{mM}\end{array}$ & $50 \cdot 2 \pm 62 \cdot 6 \mathrm{c}$ & $1 \cdot 2 \pm 2 \cdot 9 \mathrm{~b}$ \\
\hline $\begin{array}{l}\text { Atropine-PRD } \\
2.5 \mathrm{mM}\end{array}$ & $202 \cdot 2 \pm 249 \cdot 1 \mathrm{bc}$ & $1 \cdot 3 \pm 1 \cdot 8 b$ \\
\hline $\begin{array}{l}\text { Atropine-PRD } \\
0.5 \mathrm{mM}\end{array}$ & $586 \cdot 4 \pm 286 \cdot 2 \mathrm{~b}$ & $1 \cdot 8 \pm 2 \cdot 1 b$ \\
\hline
\end{tabular}

A Data are means of 6 replications (2 different experiments) per treatment combination consisting of 10 similar size cysts per well. For each treatment mean followed by the same lowercase letter do not differ significantly $(P \geqslant 0.05)$ according to Least Significant Difference test (LSD). Letters refer to mean comparisons among compounds diluted in water or PRD and differences between treatments, respectively. Area under cumulative hatch transformed into $\log _{10}(X+1)$ before analyses.

${ }^{B}$ Data not studied by ANOVA analysis because atropine treatment had no hatching.

(ftp://ftp.sanger.ac.uk/pub/pathogens/Globodera/ pallida/). Primers were designed using Primer3 v0.4.0 web server (Rozen and Skaletsky, 2000) using the sequences obtained by Jones et al. (2009). The following primers were used for the amplification of $I V g 9$ (IVG9-Fw-5'-tgaaggtgactcctctgctg-3' and IVG9-Rv-5'-acaacgttttgccgaatgta-3'); cellulase (Cell-Fw-5'-ctaactcgtggaacggaggt- $3^{\prime}$ and Cell-Rv$5^{\prime}$-ctggaaaagtgacgctgaac- $3^{\prime}$ ) and eif 44 (eifA-Fw-5'cgaaacaggaccaacaaatg- $3^{\prime}$ and eifA-Rv-5'-gttcagatcagctcccaat $\left.-3^{\prime}\right)$.

\section{Observation of quiescent and diapaused juveniles}

Cysts containing quiescent or diapaused J2 s were soaked in water for 5 days and subsequently transferred to PRD for 4 days. Eggs were extracted from mature individual cysts and $\mathrm{J} 2 \mathrm{~s}$ were forced to hatch by gently pressing on the eggshell with a needle. Light observations were conducted using a Zeiss III compound microscope with Normarski differential inference contrast with up to $1000 \mathrm{X}$ magnification. Measurements were made using a micrometer attached to a binocular in a light microscope.

\section{Statistics}

In the hatching experiments, for each treatment, the area under the curve from the cumulative number of nematodes percentage hatch (AUCPH) was estimated by trapezoidal integration (Campbell and Madden, 1990). The AUCPH were analysed by ANOVA after $\log _{10}(X+1)$ transformation. Treatment means of AUCPH were compared inside the water or PRD used for diluting the different compounds using Least Significant Difference test (LSD) at $P \leqslant 0.05$ (Gomez and Gomez, 1984). Body measurements of juveniles under different conditions were analysed by ANOVA. Treatment means of the different experiments were compared using the Least Significant Difference test (LSD) at $P \leqslant 0.05$ (Gomez and Gomez, 1984). In all cases the program Statistix 9.0 (NH Analytical Software, Roseville, MN, USA) was used for statistical calculations and transformations.

\section{RESULTS}

\section{Hatching experiments}

Hatching of quiescent (E-2009) and diapaused (E-2010) nematodes was significantly influenced $(P \leqslant 0 \cdot 05)$ by the application of PRD, although quiescent nematodes hatched to a far greater extent in response to PRD than those in diapause (Table 1, Fig. 1). Application of $8 \mathrm{Br}-\mathrm{cGMP}$ in water to quiescent nematodes (E-2009) activated hatching in a dose-dependent manner; the highest hatching was obtained in $1 \mathrm{mM}$ solution with the lowest hatching in the water treatment. Hatching of quiescent nematodes in PRD was not modified $(P \geqslant 0.05)$ by 

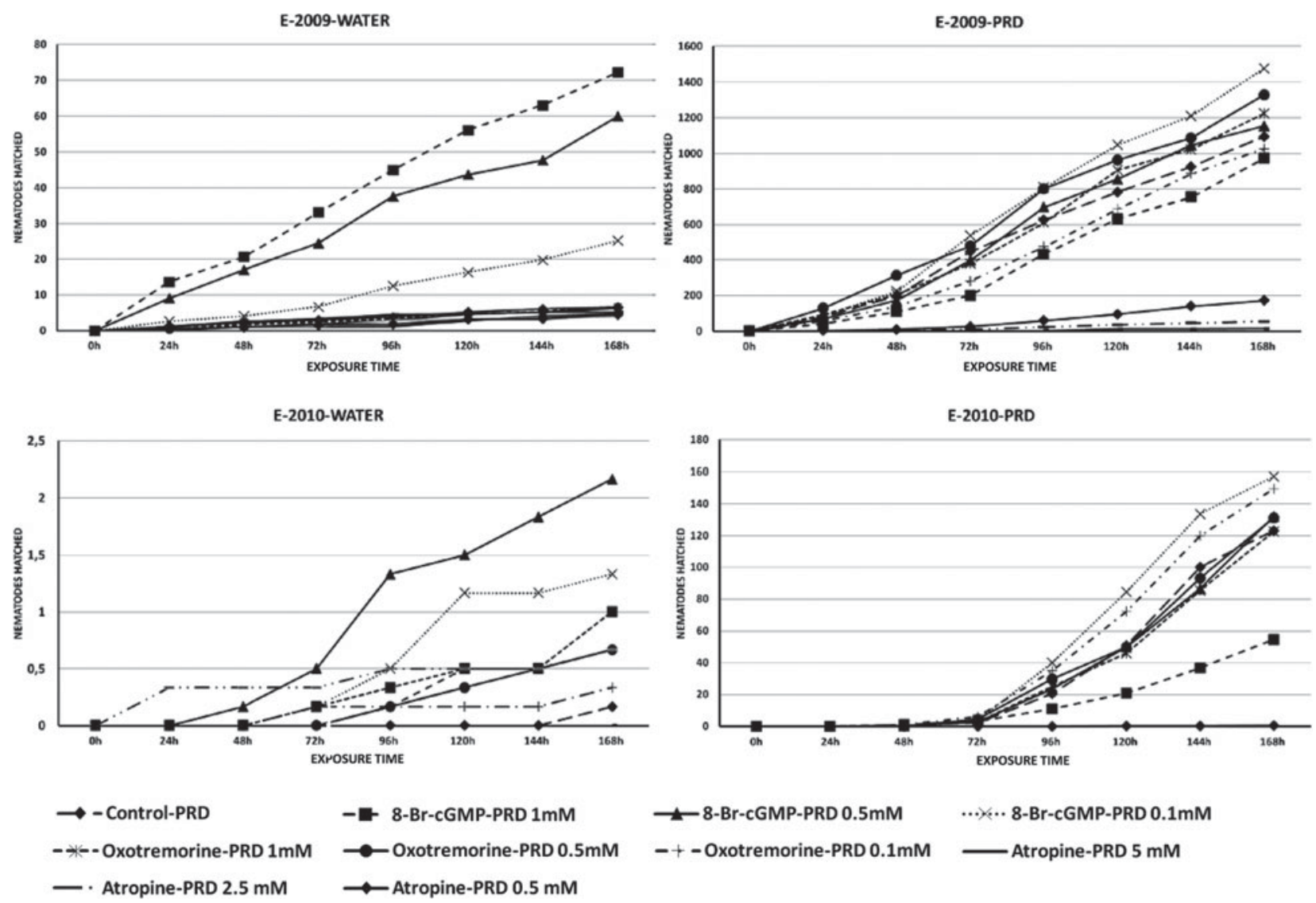

Fig. 1. Hatching of 10 cysts of Globodera pallida over 7 days of incubation at $20^{\circ} \mathrm{C}$ in different testing compounds diluted in water or in potato root diffusate (PRD). Data are means of 6 replications (2 different experiments) per treatment. (A) Population E-2009 with compounds diluted in water. (B) Population E-2010 with compounds diluted in water. (C) Population E-2009 with compounds diluted in PRD. (D) Population E-2010 with compounds diluted in PRD.

the application of $8 \mathrm{Br}-\mathrm{cGMP}$ at any concentration (Table 1, Fig. 1). Diapaused nematodes (E-2010) were not influenced $(P \geqslant 0 \cdot 05)$ at any level of the drug in water (Table 1, Fig. 1). However, the hatching of diapaused nematodes (E-2010) in PRD was significantly reduced $(P \leqslant 0 \cdot 05)$ at the highest concentration $(1 \mathrm{mM})$ of $8 \mathrm{Br}-\mathrm{cGMP}$ but not influenced by any other level ('Table 1, Fig. 1).

Atropine partially inhibited hatching in PRD in quiescent nematodes and suppressed hatching in both water and PRD in diapaused nematodes (E-2010). Quiescent nematodes (E-2009) in PRD showed a greater reduction of hatching as the levels of atropine were increased. Application of atropine to diapaused nematodes (E-2010) reduced the rate of hatching in PRD at all levels studied (Table 1, Fig. 1). However, atropine at all concentrations reduced egg viability after the removal of drug solution and the addition of PRD, with highest reduction of viability at $5 \mathrm{mM}$ atropine (data not shown).

Oxotremorine did not influence $(P \geqslant 0.05)$ the hatching of quiescent nematodes (E-2009) or diapaused nematodes (E-2010) at any level of the drug in water or PRD (Table 1, Fig. 1).
Identification of orthologues of $\mathrm{C}$. elegans diapause genes in G. pallida, M. incognita, M. hapla and B. xylophilus

Few diapause-related genes were identified as orthologues by comparison between C.elegans, M. hapla, $M$. incognita, B. xylophilus and $G$. pallida sequences using a highly stringent $\mathrm{RBH}$ analysis. Only 3 potential G. pallida orthologues (tax-2, $p d k-1$ and $d a f-21)$ were identified in comparison to C. elegans. Analysis of $B$. xylophilus revealed more potential orthologs of $C$. elegans dauer genes (tax-2, tax -4 , bra-1, akt-1, sgk-1, daf-6 and daf-21). Meloidogyne incognita contained six potential orthologs (daf-11, tax-4, pdk-1, sgk-1, daf-6 and daf-21), while M. hapla has only 2 potential orthologues (bra-1 and pdk-1) (Table 2). Bursaphelenchus xylophilus is the species with most genes related to diapause (orthologues and with high similarity) present in $C$. elegans (19 genes), followed by $M$. incognita (18 genes), G. pallida (14) and M. hapla (9 genes).

Expression of 2 genes encoding effectors ( $I V g 9$ and cellulase) (Jones et al. 2009) was highly activated in hatched juveniles (Fig. 2). These genes were slightly 
Table 2. Globodera pallida, Bursaphelenchus xylophilus, Meloidogyne incognita and M. hapla orthologues and genes with high similarity to Caenorhabditis elegans related to dauer formation

(BLASTP Reciprocal Best Hits using $\geqslant 40 \%$ identity and $\geqslant 70 \%$ coverage are in bold; other entries are genes with $\geqslant 30 \%$ identity and $\geqslant 50 \%$ coverage; - where no genes fulfil these requirements. Bit score in parentheses.)

\begin{tabular}{|c|c|c|c|c|c|}
\hline $\begin{array}{l}\text { C. elegans } \\
\text { Pathway }\end{array}$ & Protein & G. pallida & B. xylophilus & M. incognita & M. hapla \\
\hline \multicolumn{6}{|c|}{ Guanylyl cyclase pathway } \\
\hline DAF-11 & $\begin{array}{l}\text { Transmembrane } \\
\text { guanylate cyclase }\end{array}$ & $\begin{array}{l}\text { GPLIN_000580700 (628); } \\
\text { GPLIN_001400600 (584) }\end{array}$ & $01144.260(617)$ & $10772(262)$ & - \\
\hline TAX-2 & cGMP-gated channel & GPLIN_000270000 (720) & $01141.34(768)$ & $00153(261)$ & - \\
\hline TAX-4 & cGMP-gated channel & GPLIN_000399000 (692) & $00422.212(722)$ & $\begin{array}{l}00326 \text { (47); } \\
00153(571)\end{array}$ & - \\
\hline \multicolumn{6}{|l|}{ TGF $\beta$-like } \\
\hline DAF-1 & TGF- $\beta$ type I receptor & - & $00116.360(259)$ & - & - \\
\hline DAF -3 & $\begin{array}{l}\text { SMAD transcription } \\
\text { factor }\end{array}$ & - & - & - & - \\
\hline DAF-4 & TGF $\beta$ type II receptor & GPLIN_001316400(218) & $00333.171(219)$ & $03081(212)$ & $\begin{array}{l}\text { 1302.frz3.gene } 4 \\
\text { (204) }\end{array}$ \\
\hline DAF-5 & Proline rich protein & - & - & - & - \\
\hline DAF-7 & $\mathrm{BMP} / \mathrm{TGF}-\beta$ & - & - & - & - \\
\hline DAF-8 & $\begin{array}{l}\text { SMAD transcription } \\
\text { factor }\end{array}$ & - & - & - & - \\
\hline DAF-14 & $\begin{array}{l}\text { SMAD transcription } \\
\text { factor }\end{array}$ & -GPLIN_001484500 (96) & - & $03841(96)$ & - \\
\hline SCD-1 & $\begin{array}{l}\text { Glutamine rich } \\
\text { protein }\end{array}$ & - & - & - & - \\
\hline SCD-2 & Tyrosine kinase & - & - & - & - \\
\hline BRA-1 & $\mathrm{Zn}$-finger protein & - & $00351.340(175)$ & - & $\begin{array}{l}\text { 96.frz3.gene3 } \\
\text { (170) }\end{array}$ \\
\hline KIN-8 & Tyrosine kinase & - & $01063.208(521)$ & $\begin{array}{r}1176(358) \\
1199(351)\end{array}$ & - \\
\hline EGL-4 & $\begin{array}{l}\text { cGMP-dependent } \\
\text { protein kinase }\end{array}$ & - & - & - & - \\
\hline \multicolumn{6}{|c|}{ Insulin/IGF } \\
\hline DAF-2 & Insulin receptor & - & - & $08945(482)$ & - \\
\hline DAF-15 & $\begin{array}{l}\text { Ortholog RAPTOR } \\
\text { protein }\end{array}$ & GPLIN_000644600 (498) & $00579.503(501)$ & $14103(479)$ & - \\
\hline DAF-16 & $\begin{array}{l}\text { FOXO transcription } \\
\text { factor }\end{array}$ & - & $00579.503(501)$ & - & - \\
\hline DAF-18 & $\begin{array}{l}\text { Phosphoinositide 3- } \\
\text { phosphatase PTEN }\end{array}$ & - & - & $00816(342)$ & - \\
\hline DAF-28 & $\beta$-insulin & - & - & - & - \\
\hline AGE-1 & $\begin{array}{l}\text { Phosphoinositide 3- } \\
\text { kinasae }\end{array}$ & - & - & $13845(486)$ & $\begin{array}{l}\text { 100.frz3.gene14 } \\
(546)\end{array}$ \\
\hline PDK-1 & $\begin{array}{l}\text { 3-phophoinositide- } \\
\text { dependent kinase }\end{array}$ & GPLIN_000703300 (417) & $00789.39(410)$ & 03915b (435) & $\begin{array}{l}\text { 147.frz3.gene29 } \\
\text { (810) }\end{array}$ \\
\hline AKT-1 & $\begin{array}{l}\text { Serine/threonine } \\
\text { kinase }\end{array}$ & GPLIN_000475200 (404) & 00713.504 (617) & $16984(521)$ & $\begin{array}{l}\text { 1548.frz3.gene13 } \\
\text { (503) }\end{array}$ \\
\hline AKT-2 & $\begin{array}{l}\text { Serine/threonine } \\
\text { kinase }\end{array}$ & GPLIN_000475200 (378) & $00713.504(526)$ & 16984 (484) & - \\
\hline SGK-1 & $\begin{array}{l}\text { Serine/threonine } \\
\text { kinase }\end{array}$ & GPLIN_000373700(267) & $00609.3(490)$ & 15404 (487) & - \\
\hline \multicolumn{6}{|c|}{ Steroid hormone pathway } \\
\hline DAF-9 & Cytochrome P450 & - & $01144.302(304)$ & $07480(199)$ & $\begin{array}{l}\text { 727.frz3.gene3 } \\
\text { (191) }\end{array}$ \\
\hline DAF-12 & Nuclear receptor & - & 00579.493 (381) & - & - \\
\hline DAF-36 & $\begin{array}{l}\text { Rieske oxygenase, } \\
\text { hormone pathway }\end{array}$ & - & - & - & - \\
\hline \multicolumn{6}{|c|}{ Other processes } \\
\hline DAF-6 & amphid morphology & GPLIN_000159500 (733) & $00422.283(1061)$ & $04916(1024)$ & $\begin{array}{l}\text { 147.frz3.gene29 } \\
\text { (773) }\end{array}$ \\
\hline DAF-10 & WD-WAA rep & GPLIN_001144000(937) & $01145.41(712)$ & - & - \\
\hline DAF-19 & $\begin{array}{l}\text { RFX transcription } \\
\text { factor }\end{array}$ & GPLIN_000191300(225) & $01281.399(316)$ & $08233(237)$ & $\begin{array}{l}\text { 1476.frz3.gene5 } \\
\text { (233) }\end{array}$ \\
\hline DAF-21 & HSP-90 & GPLIN_000887800 (1083) & $01653.98(581)$ & 18114a (1082) & $\begin{array}{l}\text { 1972.frz3.gene3 } \\
\text { (736) }\end{array}$ \\
\hline
\end{tabular}




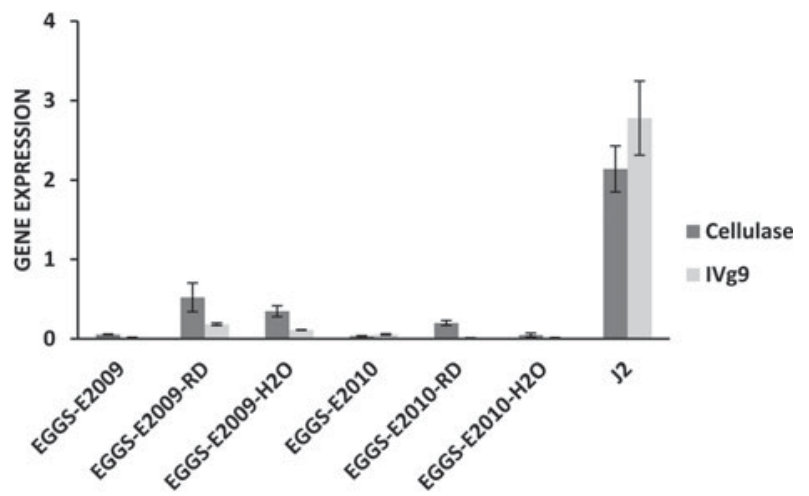

Fig. 2. Plant-parasitic nematode gene expression using second-stage juveniles (J2), dehydrated eggs from population E-2009 (eggs-E2009), dehydrated eggs from population E-2010 (eggs-E2010), eggs soaked in water for 5 days from population E-2009 (eggs-E2009- $\mathrm{H}_{2} \mathrm{O}$ ), eggs soaked in water for 5 days from population E-2010 (eggs-E2010- $\mathrm{H}_{2} \mathrm{O}$ ), eggs soaked in water for 5 days and transferred to potato root diffusate (PRD) for $24 \mathrm{~h}$ from population E-2009 (eggs-E2009-PRD), eggs soaked in water for 5 days and transferred to potato root diffusate (PRD) for $24 \mathrm{~h}$ from population E-2010 (eggs-E2010-PRD). All levels of expression are the mean of 3 biological replicates and in the format: mean \pm S.D. All genes are normalized using eif $A 4$.

up-regulated in eggs soaked in water or PRD in quiescent nematodes (E-2009). However, this upregulation was not observed in nematodes in diapause (E-2010). The activation of gene expression in quiescent eggs was stronger for cellullase than $I V g 9$. This was in contrast to the expression in $\mathrm{J} 2 \mathrm{~s}$, in which induction of $I V g 9$ was slightly higher than that of cellulase.

\section{Observation of quiescent and diapaused $\mathcal{Y} 2 \mathrm{~s}$ in response to water and PRD}

The dorsal and subventral pharyngeal gland cells responded to PRD treatment more strongly in quiescent as compared to diapaused nematodes. Differences in dorsal and subventral pharyngeal glands, the diameter of the dorsal gland cell nucleolus and the relationship between length of the body and the dorsal pharyngeal gland were statistically significant between the different treatments studied (Table 3, Fig. 3). All other measurements (body length L, width, L/width and L/subventral pharyngeal gland length) did not show any differences between the treatments $(P \geqslant 0.05)$.

The dorsal pharyngeal gland cell was longer in quiescent nematodes compared to those in diapause. This result was correlated with a lower ratio length/ dorsal pharyngeal gland length in quiescent than diapaused nematodes. The subventral pharyngeal gland was longer in diapaused nematodes soaked in PRD compared to quiescent nematodes soaked in water. Dorsal gland nucleolus diameter was clearly increased $(P \leqslant 0.05)$ by the application of PRD in quiescent nematodes (E-2009) and this treatment was significantly different from the rest of the treatments (Table 3, Fig. 3).

\section{ISCUSSION}

Many studies have demonstrated the essential role of host plant diffusates in hatching of potato cyst nematodes, with a 5-min exposure to PRD being sufficient to initiate the hatching process of G. rostochiensis (Perry and Beane, 1982). PRD alters the permeability of the lipoprotein membranes of the eggshell (Perry et al. 1982) allowing leakage of solutes, principally trehalose (Clarke et al. 1978). This reduces the osmotic pressure allowing an increase in water content and metabolic activity (Ellenby and Perry, 1976). Not all eggs in a population hatch and the majority of diapaused nematodes are insensitive to root diffusate. An excellent review of factors affecting the hatching process was provided by Perry (1998). However, the neurosecretory and genetic control of diapause and quiescence has not been investigated further in cyst nematodes. Genetic, neurosecretory and hormonal involvement in development arrest in $C$. elegans dauer larvae is well studied (Fielenbach and Antebi, 2008). In addition to environmental cues (food and temperature), a dauer pheromone is secreted at high nematode densities and this hormone promotes the formation of the dauer larvae.

Low levels of cGMP actively trigger the formation of dauer larvae, and reproductive growth when they are high, with signalling mediated through the amphidial sensory cilia (Fielenbach and Antebi, 2008). Other nematodes such as A. caninum and A. ceylanicum are recovered from developmental arrest by this compound (Brand and Hawdon, 2004). In our case, hatching of juveniles was not activated in quiescent nematodes and in the presence of PRD, and some inhibitory effect on hatching at high concentration $(1 \mathrm{mM})$ was demonstrated in the diapaused nematodes (E-2010). It is possible that the reduction of osmotic pressure produced by the presence of PRD could allow a better penetration of the compound into the amphid. However, this compound activates hatching in quiescent nematodes when the compound was diluted in water. Our results partially agree with those obtained by Atkinson et al. (1987) in which concentrations of $5 \mathrm{mM}$ of cAMP or $0.025,0.05$ and $2.5 \mathrm{mM}$ of cGMP reduced significantly hatching of $G$. rostochiensis in a $1 / 10$ dilution of PRD. However, differences in inhibitory effects have been found between cAMP and cGMP after the removal of the chemical and the addition of PRD (Atkinson et al. 1987). One possible explanation for these differences is the different populations used, age and different species (G. pallida vs G. rostochiensis). Oxotremorine, a synthetic muscarinic agonist did not 


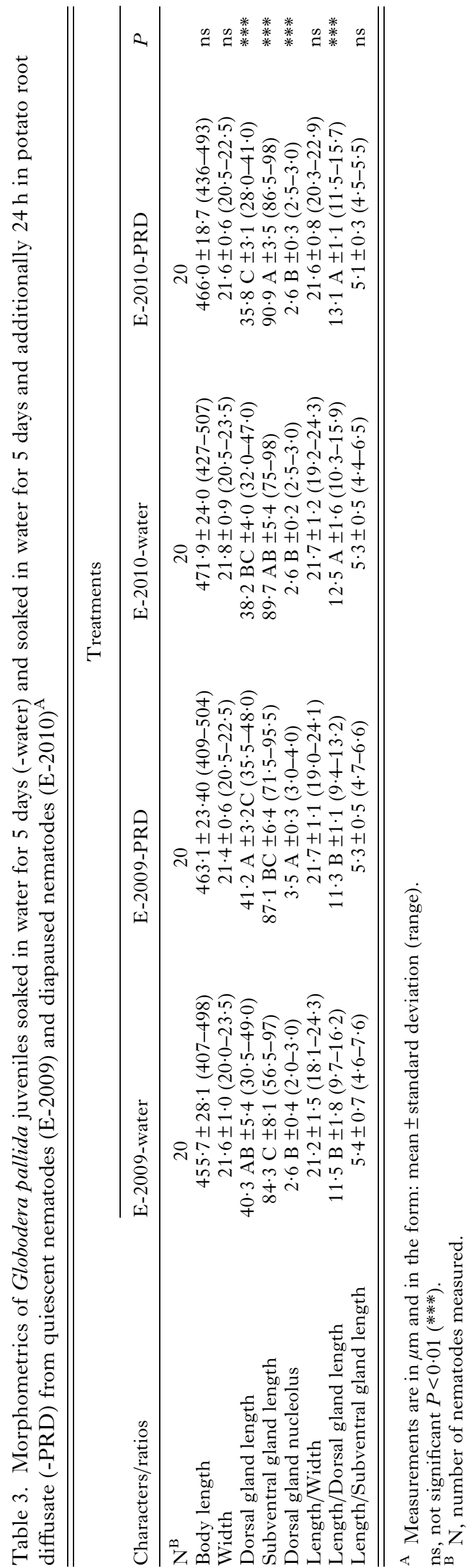

induce any effect on the hatching of G. pallida which differs from results obtained in other nematodes (Tissenbaum et al. 2000). Muscarinic agonists promote insulin release both in vivo and in vitro in mammals (Miller, 1981; Hawdon and Schad, 1993). Insulin seems not to play a role in hatching of either diapaused or quiescent G. pallida, suggesting limited effects of this drug in the release of insulin-like factors from secretory cells. However, atropine partially inhibited hatching at high concentrations $(5 \mathrm{mM})$ in the quiescent population (E-2009) and completely inhibited hatching in the diapaused population (E-2010). Atropine inhibits all subtypes of the muscarinic acetylcholine receptor and not nicotinic receptors in mammals, and the dauer recovery is almost completely inhibited in other nematodes at lower $(1 \mathrm{mM})$ or higher levels of the drug $(5 \mathrm{mM})$ (Tissenbaum et al. 2000). In our case, hatching inhibition may also be linked to a high rate of mortality at the levels studied, especially at 2.5 and $5 \mathrm{mM}$ as determined by hatching observations following the removal of the drugs and soaking the cysts in PRD (data not shown). It is possible that in $G$. pallida this phenomenon has a different neuronal pathway to the TGF- $\beta$ signalling pathway, which in $C$. elegans dauer recovery acts convergently with the insulin-like (or muscarinic) pathway or a different atropine-resistant pathway could explain the partial but not complete inhibition of hatching.

Sequence comparisons of diapause-related genes in $G$. pallida with those from $C$. elegans revealed few genes that were strong candidates for orthologues of diapause-related genes from $C$. elegans. Surprisingly, few orthologues were found in the other plantparasitic nematodes previously studied, even in $B$. xylophilus, which is more closely related to C. elegans (Holterman et al. 2006) and which has a dauer stage in its life cycle. No clear pathways or gene patterns seem conserved in the plant-parasitic nematodes studied. This result is shown by the absence of genes for orthologues/homologues for the signalling insulin, TGF- $\beta$ and steroid hormone pathways. It seems that these pathways are partially represented, because the major signals are not present in the nematodes studied (daf-7 and $d a f-28)$ and the respective receptors are only present in some species, including daf-1(B. xylophilus), daf-4 (G. pallida, B. xylophilus, $M$. incognita and $M$. hapla), daf-2 (M. incognita) and daf-12 (B. xylophilus). However, the guanylyl cyclase pathway is mainly conserved (with the exception of $M$. hapla), possibly because of its important role in detection of environmental cues. The use of other molecules or genes and the phylogenetic separation of these species from $C$. elegans could also make amino-acid sequence comparison difficult. However, some genes may have been missed during genome assembly or annotation. Kinases potentially related to the insulin pathway seem mainly conserved. PDK-1 is much conserved 

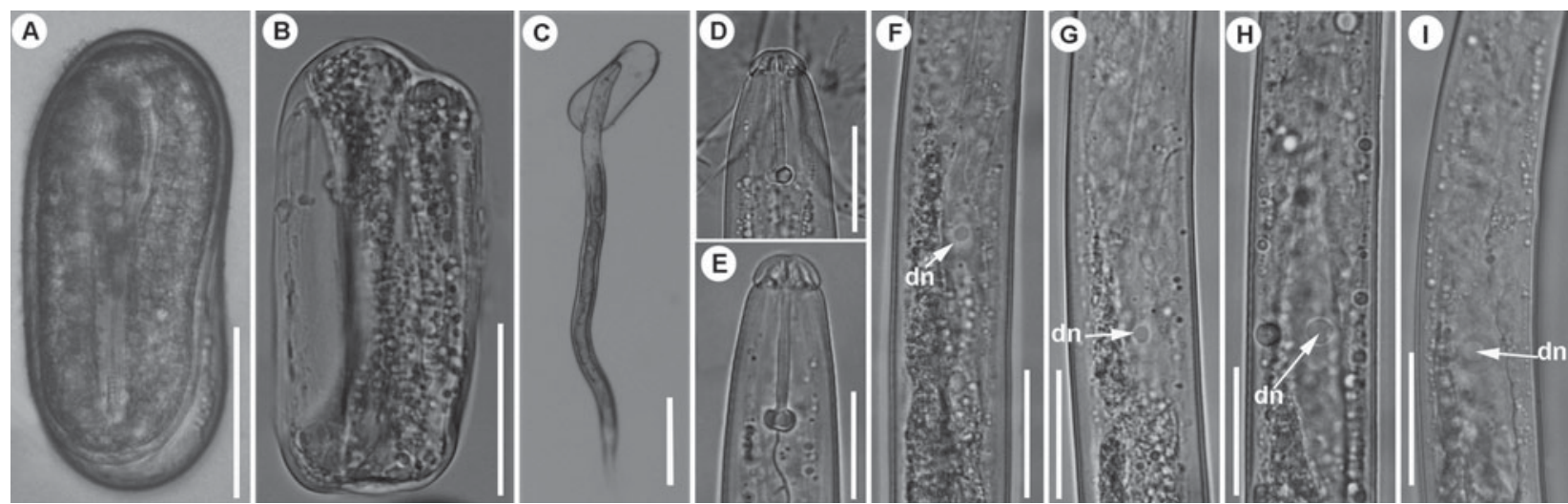

Fig. 3. Light micrographs of eggs and dorsal gland second-stage juvenile nucleolus of Globodera pallida under different treatments. (A) Eggs hydrated after 5 days. (B) Egg dehydrated. C) Second-stage juvenile hatching from the egg. (D and E) Second-stage juvenile anterior region. ( $F$ and $G$ ) Dorsal gland nucleolus of second-stage juvenile from E-2009 hydrated after 5 day in water. (H and I) Dorsal gland nucleolus of second-stage juvenile from E-2009 hydrated after 5 days in water and soaked in root potato root diffusate for 4 days. Abbreviation: dn, dorsal gland nucleolus. Scale bars: $\mathrm{A}, \mathrm{B}=50$ microns; $\mathrm{C}=100$ microns; $\mathrm{D}-\mathrm{I}=20$ microns.

within the nematodes studied and acts downstream of AGE-1/PI3 K and upstream of the AK'T-1 and AKT-2 kinases (www.wormbase.org, 2012). While SGK-1 forms a complex with the AKT kinases and phosphorylates DAF-16 (www.wormbase.org, 2012). The surprising lack of good gene candidates similar to DAF-16 (with the exception of $M$. incognita) suggests that these genes could have other functions in nematode development. The insulin/IGF pathway in the plant-parasitic nematodes is not the same as that described for C.elegans and it is corroborated in the lack of hatching in the oxotremorine eggs exposed to PRD. Daf-6 is required for the normal function of the non-neuronal amphidial sheath cells of the amphid and the outer labial sensilla (www.wormbase.org, 2012). Daf-6 mutants show a disruption in the joining of the amphid sheath and socket cells to form the receptor channel, displaying defects in several distinct functions including formation of dauer larvae, chemotaxis, osmotic avoidance, male mating, negative regulation of lifespan, negative regulation of ASJ's axonal growth late in development and dye uptake by amphids and phasmids (www.wormbase.org, 2012). Daf-21 activity is required for larval development, negative regulation of dauer larva formation, and a number of specific chemosensory behaviours (www. wormbase.org, 2012). Daf-21 sensory defects can be rescued by a cyclic GMP analogue, suggesting regulation in chemosensory behaviours (www. wormbase.org, 2012). Our results disagree with the results published by Opperman et al. (2008) and Kikuchi et al. (2011), in which the majority of the diapause genes studied were strongly supported as orthologues. However, we used a more stringent filtering method than those used in the previous studies. Differences in these parameters could affect the results obtained in the comparisons between nematode genes. These results suggest that different or modified pathways may be used by plant nematodes to control this physiological event.

In our RT-PCR experiments, unhatched $\mathrm{J} 2 \mathrm{~s}$ did not show a clear activation of parasitism gene expression in the presence of PRD, with only a slight increase in expression observed in quiescent nematodes exposed to PRD. However, the preparation for parasitism gene expression is indicated by changes in the diameter of the nucleolus in quiescent nematodes exposed to PRD. No expression of parasitism genes was detected in nematodes in diapause and the gland cells of these nematodes did not respond morphologically to PRD. Similar results were obtained by measurement of the nucleolus diameter from the dorsal gland cell and by acridine orange staining using quiescent populations of $G$. rostochiensis soaked in root diffusate (Atkinson et al. 1987; Blair et al. 1999). Additionally, some authors have proposed that the real analogue of the dauer stage in cyst nematodes could be the J2, but gene expression studies using microarrays did not support this (Elling et al. 2007).

It has been suggested that diapause in $G$. rostochiensis is initiated by signals from the plant during the growing season (Hominick et al. 1985). Nematodes develop inside the female and are arrested at J2, after moulting from J1. This development has been observed in eggs outside the female and the arrest point remains in the $\mathrm{J} 2$ (Langeslag et al. 1982; Palomares-Rius et al., unpublished results). Preliminary results in our group have shown that this arrest in the J2 stage is not broken by PRD. However, a second generation in the field and in controlled conditions has been detected in G. pallida if the host potato plant is healthy and in warmer temperatures (Jiménez-Pérez et al. 2009). The low number of $G$. pallida orthologues of $C$. elegans genes related to dauer formation suggests that these genes are not involved in the inhibition of hatching of diapaused eggs. The position of individual cysts in 
the root system may influence the syncytium establishment and access to an adequate food source, as well as egg production (possible egg condition in relation to non-diapaused, diapaused or quiescence in individual cysts within a population) and the host physiological condition (active growth vs senescence) are the main focus for future research to clarify conditions which affect this complicated biological survival strategy in an important crop pest.

\section{ACKNOWLEDGEMENTS}

The authors thank the Spanish Ministry of Education for funding to the first author under the 'Ayudas para la movilidad postdoctoral en centros extranjeros' scheme. The James Hutton Institute receives funding from the Scottish Government. Statistical advice from Jim McNicol is gratefully acknowledged (BIOSS, UK).

\section{REFERENCES}

Altschul, S. F, Gish, W., Miller, W., Myers, E. W. and Lipman, D. J. (1990). Basic local alignment search tool . Fournal of Molecular Biology 215, $403-410$.

Atkinson, H. J., Taylor, J. D. and Fowler, M. (1987). Changes in the second stage juveniles of Globodera rostochiensis prior to hatching in response to potato root diffusate. Annals of Applied Biology 110, 105-114.

Banyer, R. J. and Fisher, J. M. (1971). Seasonal variation in hatching of eggs of Heterodera avenae. Nematologica 17, 225-236.

Bird, A.F. and Buttrose, M. S. (1974). Ultrastructural changes in the nematode Anguina tritici associated with anhydrobiosis. Fournal of Ultrastructural Research 48, 177-189.

Blair, L., Perry, R. N., Oparka, K. and Jones, J. (1999). Activation of transcription during the hatching process of the potato cyst nematode Globodera rostochiensis. Nematology 1, 103-111.

Brand, A. and Hawdon, J. M. (2004). Phosphoinositide-3-OH-kinase inhibitor LY294002 prevents activation of Ancylostoma caninum and Ancylostoma ceylanicum third-stage infective larvae. International fournal for Parasitology 34, 909-914.

Campbell, C. L. and Madden, L. (1990). Introduction to Plant Disease Epidemiology. John Wiley \& Sons, New York, USA.

Clarke, A. J., Perry, R. N. and Hennessy, J. (1978). Osmotic stress and the hatching of Globodera rostochiensis. Nematologica 24, 384-392.

Ellenby, C. and Perry, R. N. (1976). The influence of the hatching factor on the water uptake of the second stage larva of the potato cyst nematode Heterodera rostochiensis. Fournal of Experimental Biology 64, 141-147.

Elling, A. A., Mitreva, M., Recknor, J., Gai, X., Martin, J., Maier, T.R., McDermott, J.P., Hewezi, T., McK Bird, D., Davis, E. L., Hussey, R. S., Nettleton, D., McCarter, J.P. and Baum, T. J. (2007). Divergent evolution of arrested development in the dauer stage of Caenorhabditis elegans and the infective stage of Heterodera glycines. Genome Biology 8, R211. doi: 10.1186/gb-2007-8-10-r211.

Fielenbach, N. and Antebi, A. (2008). C. elegans dauer formation and the molecular basis of plasticity. Genes and Development 22, 2149-2165 doi:10.1101/gad.1701508

Goecks, J., Nekrutenko, A., Taylor, J. and The Galaxy Team. (2010). Galaxy: a comprehensive approach for supporting accessible, reproducible, and transparent computational research in the life sciences. Genome Biology 25,11: R86.

Gomez, K. A. and Gomez, A. A. (1984). Statistical Procedures for Agricultural Research, 2nd Edn. John Wiley \& Sons. New York, USA. Hawdon, J. M. and Datu, B. (2003). The second messenger cyclic GMP mediates activation in Ancylostoma caninum infective larvae. International Fournal for Parasitology 33, 787-793.

Hawdon, J. M. and Schad, G. A. (1993). Ancylostoma caninum Glutathione stimulates feeding in third stage larvae by a sulfhydryl independent mechanism. Experimental Parasitology 77, 489-491.

Holterman, M., van der Wurff, A., van den Elsen, S., van Megen, H., Bongers, T., Holovachov, O., Bakker, J. and Helder, J. (2006). Phylumwide analysis of SSU rDNA reveals deep phylogenetic relationships among nematodes and accelerated evolution toward crown clades. Molecular Biology and Evolution 23, 1792-1800.

Hominick, W. M., Forrest, J. M. S. and Evans, A. A. F. (1985). Diapause in Globodera rostochiensis and variability in hatching trials. Nematologica 31, 159-170.

Hu, P. J. (2007). Dauer. In WormBook (ed. Riddle, L. R.), doi/10.1895/ wormbook.1.144.1, http://www.wormbook.org.

Huang, S. C., Chan, D. T. Y., Smyth, D. J., Ball, G., Gounaris, K. and Selkirk, M.E. (2010). Activation of Nippostrongylus brasiliensis infective larvae is regulated by a pathway distinct from the hookworm Ancylostoma caninum. International fournal for Parasitology 40, 1619-1628.

Jiménez-Pérez, N.Crozzoli, R. and Greco, N. (2009). Life-cycle and emergence of second stage juveniles from cysts of Globodera rostochiensis in Venezuela. Nematologia Mediterranea 37: 155-160.

Jones, J. T., Kumar, A., Pylypenko, L. A., Thirugnanasambandam, A., Castelli, L., Chapman, S., Cock, P. J., Grenier, E., Lilley, C. J., Phillips, M.S. and Blok, V.C. (2009). Identification and functional characterisation of effectors in Expressed Sequence Tags from various life cycle stages of the potato cyst nematode Globodera pallida. Molecular Plant Pathology 10, 815-828

Kikuchi, T., Cotton, J. A., Dalzell, J. J., Hasegawa, K., Kanzaki, N., McVeigh, P., Takanashi, T., Tsai, I. J., Assefa, S. A., Cock, P. J. A., Dan Otto, T., Hunt, M., Reid, A. J., Sanchez-Flores, A., Tsuchihara, K., Yokoi, T., Larsson, M. C., Miwa, J., Maule, A. G., Sahashi, N., Jones, J. T. and Berriman, M. (2011). Genomic insights into the origin of parasitism in the emerging plant pathogen Bursaphelenchus xylophilus. PLoS Pathogens 7, e1002219.

Langeslag, M., Mugniery, D. and Fayet, G. (1982). Développement embryonnaire de Globodera rostochiensis et $G$. pallida en fonction de la température, en conditions contrôlées et naturelles. Revue Nématologie $\mathbf{5}$, 103-109.

Miller, R.E. (1981). Pancreatic neuroendocrinology: peripheral neural mechanisms in the regulation of the Islets of Langerhans. Endocrine Reviews 2, 471-494

Muhammad, Z. (1994). Diapause in the nematode G. pallida. European Fournal of Plant Pathology 100, 413-423.

Opperman, C. H., Bird, D. M., Williamson, V.M., Rokhsar, D.S., Burke, M., Cohn, J., Cromer, J., Diener, S., Gajan, J., Graham, S., Houfek, T. D., Liu, Q., Mitros, T., Schaff, J., Schaffer, R., Scholl, E., Sosinski, B. R., Thomas, V.P. and Windham, E. (2008). Sequence and genetic map of Meloidogyne hapla: A compact nematode genome fro plant parasitism. Proceedings of the National Academy of Sciences, USA 105, 14802-14807.

Perry, R. N. (1989). Dormancy and hatching of nematode eggs. Parasitology Today 5, 377-383.

Perry, R. N. (1998). The physiology and sensory perception of potato cyst nematodes, Globodera species. In Potato Cyst Nematodes: Biology, Distribution and Control (ed. Marks, R. J. and Brodie, B. B.), pp. 27-49. CABI Publishing, Wallingford, UK.

Perry, R. N. and Beane, J. (1982). The effect of brief exposure to potato root diffusate on the hatching of Globodera rostochiensis. Revue de Nematologie 5, 221-224

Perrry, R. N. and Gaur, H.S. (1996). Host plant influences on the hatching of cyst nematodes. Fundamental and Applied Nematology 19, 505-510.

Perry, R. N. and Moens (2011). Survival of parasitic nematodes outside the host. In Molecular and Physiological Basis of Nematode Survival (ed. Perry, R. N. and Wharton, D. A.), pp. 1-27. CABI Publishing, Wallingford, UK. Perry, R. N., Wharton, D. A. and Clarke, A. J. (1982). The structure of the egg-shell of Globodera rostochiensis (Nematoda: Tylenchida). International Fournal for Parasitology 12, 481-485.

Pylypenko, L. A., Uehara, T., Phillips, M. S., Sigareva, D.D. and Blok, V. C. (2005). Identification of Globodera rostochiensis and G. pallida in the Ukraine by PCR. European Fournal of Plant Pathology 111, 39-46. Rozen, S. and Skaletsky, H. J. (2000). Primer3 on the WWW for general users and for biologist programmers. In Bioinformatics Methods and Protocols: Methods in Molecular Biology (ed. Krawetz, S. and Misener, S.), pp. 365-368. Humana Press, Totowa, NJ, USA.

Spears, J. F. (1968). The golden nematode handbook: survey, laboratory, control, and quarantine procedures. USDA Agriculture Handbook. No. 353 Tissembaum, H. A., Hawdon, J., Perregaux, M., Hotez, P., Guarente, L. and Ruvkun, G. (2000). A common muscarinic pathway for diapause recovery in the distantly related nematode species Caenorhabditis elegans and Ancylostoma caninum. Proceedings of the National Academy of Sciences, USA 97, 460-465. 